\title{
14-3-3 $\gamma$ regulates cell viability and milk fat synthesis in lipopolysaccharide-induced dairy cow mammary epithelial cells
}

\author{
LIXIN LIU $^{1,2}$, LI ZHANG $^{1}$, YE LIN $^{1}$, YANJIE BIAN $^{1}$, XUEJUN GAO $^{1}$, BO QU $^{1}$ and QINGZHANG LI $^{1}$ \\ ${ }^{1}$ Key Laboratory of Dairy Science of Education Ministry, Northeast Agricultural University, Harbin, \\ Heilongjiang 150030; ${ }^{2}$ College of Pharmacy, Jiamusi University, Jiamusi, Heilongjiang 154007, P.R. China
}

Received November 21, 2014; Accepted December 22, 2015

DOI: $10.3892 /$ etm.2016.3029

\begin{abstract}
Our previous study demonstrated that $14-3-3 \gamma$ overexpression was able to inhibit the production of lipopolysaccharide (LPS)-induced cytokines in dairy cow mammary epithelial cells (DCMECs) by inhibiting the activation of nuclear factor- $\kappa \mathrm{B}(\mathrm{NF}-\kappa \mathrm{B})$ signaling pathways. However, the association between 14-3-3 $\gamma$ overexpression and milk fat synthesis in LPS-induced DCMECs remains unclear. Therefore, the present study investigated the effect of 14-3-3 $\gamma$ on cell viability and milk fat synthesis in LPS-induced DCMECs. The results of the MTT assay and lactate dehydrogenase activity assay demonstrated that 14-3-3 $\gamma$ overexpression was able to attenuate LPS-induced cytotoxicity in DCMECs, and increase the viability of the cells. In addition, the results of reverse transcription-quantitative polymerase chain reaction suggested that mRNA expression levels of genes associated with milk fat synthesis, including sterol regulatory element binding protein (SREBP1), peroxisome proliferator-activated receptor- $\gamma$ (PPARG), cluster of differentiation 36, acetyl-coA carboxylase (ACC), fatty acid synthase (FAS) and fatty acid binding protein-3, were significantly upregulated in cells overexpressing the $14-3-3 \gamma$ protein. In addition, as compared with the LPS-treated group, the activities of FAS and ACC were significantly increased. Furthermore, western blotting demonstrated that $14-3-3 \gamma$ overexpression enhanced the protein expression levels of phosphorylated SREBP1 and PPARG. These results suggested that high levels of $14-3-3 \gamma$ protein were able to attenuate LPS-induced cell damage and promote milk fat synthesis in LPS-induced DCMECs by increasing the
\end{abstract}

Correspondence to: Professor Qingzhang Li, Key Laboratory of Dairy Science of Education Ministry, Northeast Agricultural University, 59 Mucai Street, Xiangfang, Harbin, Heilongjiang 150030, P.R. China

E-mail: qzli@neau.edu.cn

Abbreviations: LPS, lipopolysaccharide; DCMEC, dairy cow mammary epithelial cell; SARA, subacute ruminal acidosis; MFD, milk fat depression

Key words: 14-3-3 $\gamma$, dairy cow mammary epithelial cells, cell viability, milk fat synthesis, lipopolysaccharide cell viability and upregulating the expression levels of transcription factors associated with milk fat synthesis.

\section{Introduction}

Subacute ruminal acidosis (SARA), which is a common disease in high yielding dairy cows that receive highly digestible diets, has a high economic impact (1). SARA increases the content of free lipopolysaccharide (LPS) in the rumen by increasing the lysis of gram-negative bacteria (2). LPS is the primary component of the gram-negative bacterial outer membrane, and is a key factor that induces the release of proinflammatory cytokines, including tumor necrosis factor (TNF)- $\alpha$, interleukin (IL)-1 $\beta$, and IL-6 (3), which in turn activate hepatocytic receptors and initiate the synthesis of acute phase proteins (4). In addition, LPS induces the activation of nuclear factor (NF)- $\kappa \mathrm{B}$, which translocates into the nucleus and regulates the expression of genes involved in cellular differentiation, proliferation, inflammation and apoptosis $(5,6)$. Furthermore, LPS has been shown to regulate lactation and the synthesis of milk fat (7); previous studies associated rumen LPS-mediated inflammatory responses with milk fat depression (MFD) syndrome in lactating dairy cows, which is characterized by reduced milk fat synthesis and milk energy efficiency $(8,9)$. Previous in vitro experiments have demonstrated that LPS is capable of inhibiting fatty acid synthase (FAS), acetyl-coA carboxylase (ACC) and peroxisome proliferator-activated receptor- $\gamma$ (PPARG) gene expression levels, thereby inhibiting the synthesis of fatty acids (10-12). Therefore, inhibiting LPS-induced inflammatory cytokine production is a formidable challenge that may improve milk fat content and milk quality.

$14-3-3 \gamma$ is an influential member of the 14-3-3 family, which are localized to the cell nucleus (13) and have important roles in coordinating the progression of cells $(14,15)$. Previous studies have reported that 14-3-3 $\gamma$ overexpression promotes the viability of DCMECs (16) and $14-3-3 \gamma$ may serve a crucial function in the regulation of LPS-induced myocardial injury $(17,18)$. Our previous study (11) demonstrated that $14-3-3 \gamma$ was able to inhibit the production of LPS-induced cytokines in dairy cow mammary epithelial cells (DCMECs) by inhibiting the activation of NF- $\kappa B$ signaling pathways. However, to the best of our knowledge, the mechanism underlying the role of 14-3-3 $\gamma$ in LPS-induced 
DCMEC injury, and the association between 14-3-3 $\gamma$ and milk fat synthesis in LPS-induced DCMECs, has yet to be investigated.

The present study aimed to investigate the protective effect of 14-3-3 $\gamma$ on LPS-induced DCMECs and the effects of 14-3-3 $\gamma$ on milk fat synthesis. A grapevine chrome mosaic virus (GCMV)/internal ribosome entry site (IRES)/enhanced green fluorescent protein (EGFP)-14-3-3 $\gamma$ expression vector was constructed and transfected into DCMECs in order to evaluate the ability of 14-3-3 $\gamma$ to protect against LPS-induced cell damage, and to determine its effect on the expression levels of milk fat synthesis-associated genes.

\section{Materials and methods}

Ethics statement. All experiments in the present study were approved by the Northeast Agricultural University Provincial Experimental Animal Management Committee (Harbin, China) and were performed in accordance with the guidelines of this committee.

Chemicals and reagents. LPS (Escherichia coli 0111:B4) and MTT were obtained from Sigma-Aldrich (St. Louis, MO, USA). Fetal bovine serum (FBS) and Dulbecco's modified Eagle's medium: F12 (DMEM/F12) base were obtained from Thermo Fisher Scientific, Inc. (Gibco; Waltham, MA, USA). Antibodies against PPARG, phosphorylated (p)-PPARG, sterol regulatory element binding protein (SREBP1) and $\beta$-actin were purchased from Santa Cruz Biotechnology, Inc. (Dallas, TX, USA). Anti-p-SREBP1 was purchased from Cell Signaling Technology Inc. (Danvers, MA, USA) and horseradish peroxidase-conjugated goat anti-rabbit and anti-mouse secondary antibodies were obtained from Beijing Biosynthesis Biotechnology Co., Ltd. (Beijing, China). ACC (GMS50510.2 v.A) and FAS (GMS50509.1 v.A) activity detection kits were obtained from Shanghai GenePharma Co. Ltd. (Shanghai, China).

Culture of DCMECs. Purified DCMECs were obtained from the Key Laboratory of Dairy Science of Education Ministry at Northeast Agricultural University. The cells were incubated at $37^{\circ} \mathrm{C}$ in an atmosphere containing $5 \% \mathrm{CO}_{2}$ in basic culture medium (DMEM/F12 base with $10 \%$ FBS, $100 \mathrm{U} / \mathrm{ml}$ penicillin (Harbin Pharmaceutical Group Co., Ltd., Harbin, China) and $100 \mathrm{U} / \mathrm{ml}$ streptomycin (Dalian Merro Pharmaceutical Factory, Dalian, China $(19,20)$.

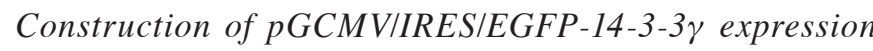
vectors. The full-length cDNA encoding bovine 14-3-3 $\gamma$ was generated by polymerase chain reaction (PCR) using total RNA extracted from DCMECs. The final reaction volume of $20 \mu \mathrm{l}$ contained $10 \mu \mathrm{l} \mathrm{SYBR}{ }^{\circledR}$ Premix Eq Taq ${ }^{\mathrm{TM}}, 0.4 \mu \mathrm{l}$ forward primer $(10 \mu \mathrm{M}), 0.4 \mu \mathrm{l}$ reverse primer $(10 \mu \mathrm{M}), 0.4 \mu \mathrm{l}$ Rox reference dye (50X), $2 \mu \mathrm{l}$ cDNA template and $6.8 \mu \mathrm{l}$ diethylpyrocarbonate-treated water. Reaction conditions were as follows: $94^{\circ} \mathrm{C}$ for $5 \mathrm{~min}$, followed by 35 cycles of $94^{\circ} \mathrm{C}$ for $30 \mathrm{sec}, 62^{\circ} \mathrm{C}$ for $30 \mathrm{sec}$ and $72^{\circ} \mathrm{C}$ for $60 \mathrm{sec}$, and finally $72^{\circ} \mathrm{C}$ for $10 \mathrm{~min}$. Primers were purchased from the Beijing Genomics Institute and the sequences were as follows: Forward, 5'-GAT CATCCTCGTCCGG-3' and reverse, 5'-CAGTCCACCTGG
GGGC-3'. The PCR products were digested with EcoRI and BamHI (both Takara Biotechnology Co., Ltd., Dalian, China) and were subsequently subcloned into the multiple cloning sites of the pGCMV/IRES/EGFP expression vector (Ambion; Thermo Fisher Scientific, Inc.), as previously described (16).

Transfection of $p$ GCMV/IRES/EGFP-14-3-3 $\gamma$. DCMECs were cultured in 6-well plates $\left(3 \times 10^{5}\right.$ cells $\left./ \mathrm{cm}^{2}\right)$ until $80-90 \%$ cell density was reached. pGCMV/IRES/EGFP-14-3-3 $\gamma$ or pGCMV/IRES/EGFP expression vectors were transfected into cells using Lipofectamine ${ }^{\mathrm{TM}} 2000$ (Thermo Fisher Scientific, Inc.), according to the manufacturer's protocol. Briefly, $4 \mu \mathrm{g}$ pGCMV/IRES/EGFP-14-3-3 $\gamma$ plasmid and $10 \mu 1$ Lipofectamine $^{\mathrm{TM}} 2000$ were diluted using $250 \mu \mathrm{l}$ Gibco Opti-MEM I medium (Thermo Fisher Scientific, Inc.) and the complexes were incubated at room temperature for $20 \mathrm{~min}$, prior to addition to the cell cultures. The cultures were then incubated with serum- and antibiotic-free DMEM/F12 medium at $37^{\circ} \mathrm{C}$ for $4 \mathrm{~h}$, after which the medium was discarded and fresh culture medium was added. Following transfection for $24 \mathrm{~h}$, the mRNA expression levels of 14-3-3 $\gamma$ were measured, as previously described (11).

Transfection of small interfering RNAs (siRNAs). 14-3-3 $\gamma$ siRNAs and negative scrambled control siRNA were purchased from Shanghai GenePharma Co. Ltd. The 14-3-3 $\gamma$ siRNA had the following sequence: Sense, 5'-CCC UUA ACUACUCCGUCUUTT-3' and antisense, 5'-AAG ACGGAGUAGUUAAGGGTT-3'. The negative scrambled control siRNA lacked significant sequence homology to any gene and had the following sequence: Sense, 5'-UUC UUGAACGUGUCACGUTT-3' and antisense, 5'-ACGUGA CACGUUCGGAGAATT-3'. DCMECs were cultured in 6-well plates until they reached a cell density of $80-90 \%$. siRNA-14-3-3 $\gamma$ or negative control were transfected into the cells using Lipofectamine ${ }^{\mathrm{TM}} 2000$, according to the manufacturer's protocol. Briefly, $2 \mu 1$ siRNA-14-3-3 $\gamma$ and $5 \mu 1$ Lipofectamine $^{\mathrm{TM}} 2000$ were diluted using $200 \mathrm{ml}$ Opti-MEM I medium, after which the mixture was incubated at room temperature for $20 \mathrm{~min}$, prior to addition into the wells. The cultures were then incubated with serumand antibiotic-free medium at $37^{\circ} \mathrm{C}$ for $4 \mathrm{~h}$, after which the medium was discarded and fresh culture medium with was added. Transfection efficiency was observed under a fluorescence microscope (CKX41; Olympus Corporation, Tokyo, Japan) according to the number of fluorescent cells.

MTT assay. The viability of DCMECs was measured using the MTT assay. Briefly, DCMECs were transfected with with pGCMV/IRES/EGFP-14-3-3 $\gamma$, pGCMV-IRES-EGFP, 14-3-3 $\gamma$ siRNA or negative control siRNA for $24 \mathrm{~h}$. Transfected cells were seeded into 96 -well plates at $1 \times 10^{5}$ cells/well, followed by $24 \mathrm{~h}$ culturing in the presence or absence of $1 \mu \mathrm{g} / \mathrm{ml}$ LPS. Subsequently, the cells were washed with D-Hanks, and MTT (5 $\mathrm{mg} / \mathrm{ml}$ in PBS; all Sigma-Aldrich) was added to each well and incubated for $4 \mathrm{~h}$ at $37^{\circ} \mathrm{C}$. The reaction was stopped by the addition of $100 \mu \mathrm{l}$ dimethyl sulfoxide (Amresco, LLC, Solon, $\mathrm{OH}, \mathrm{USA}$ ). After the mixture was oscillated for $15 \mathrm{~min}$, absorbance was measured at $570 \mathrm{~nm}$ using a spectrophotometer (DU800; Beckman Coulter, Inc., Brea, CA, USA). 
Table I. Primer sequences for the reverse transcription-quantitative polymerase chain reaction.

\begin{tabular}{|c|c|c|c|}
\hline Gene name & Accession number & Primer sequence $\left(5^{\prime}-3^{\prime}\right)$ & Product size (bp) \\
\hline $14-3-3 \gamma$ & BC153255.1 & $\begin{array}{l}\text { Forward: GAATGAGCCACTGTCCAA } \\
\text { Reverse: GCACATCCTGACATACGG }\end{array}$ & 171 \\
\hline SREBP1 & NM_001113302.1 & $\begin{array}{l}\text { Forward: GTAGCAGCGGTGGAAGT } \\
\text { Reverse: GCAGCGGCTCTGGATT }\end{array}$ & 67 \\
\hline PPARG & NM_181024.2 & $\begin{array}{l}\text { Forward: GCAGCGGCTCTGGATT } \\
\text { Reverse: ATAGTGGAACCCTGACG }\end{array}$ & 170 \\
\hline CD36 & NM_001046239.1 & $\begin{array}{l}\text { Forward: GGAAAGGACGACATAAGCAAAG } \\
\text { Reverse: TCAACAAAAGGTGGAAATGAGG }\end{array}$ & 187 \\
\hline $\mathrm{ACC}$ & NM_174224.2 & $\begin{array}{l}\text { Forward: AGACAAACAGGGACCATT } \\
\text { Reverse: AGGGACTGCCGAAACAT }\end{array}$ & 141 \\
\hline FAS & NM_001012669.1 & $\begin{array}{l}\text { Forward: CCACGGCTGTCGGTAAT } \\
\text { Reverse: CGCTCCCACTCATCCTG }\end{array}$ & 171 \\
\hline FABP3 & NM_174313.2 & $\begin{array}{l}\text { Forward: GAACTCGACTCCCAGCTTGAA } \\
\text { Reverse: AAGCCTACCACAATCATCGAAG }\end{array}$ & 214 \\
\hline$\beta$-actin & NM_173979 & $\begin{array}{l}\text { Forward: CCGCAAGGACCTCTACGC } \\
\text { Reverse: ATGCCAATCTCATCTCGTTTT }\end{array}$ & 206 \\
\hline
\end{tabular}

SREBP, sterol regulatory element binding protein; PPARG, peroxisome proliferator-activated receptor gamma; CD36, cluster of differentiation 36; ACC, acetyl-CoA carboxylase; FAS, fatty acid synthase; FABP, fatty acid binding protein.

Lactate dehydrogenase ( $L D H)$ activity assay. Following transfecion, DCMECs were incubated with antibiotic-free DMEM/F12 medium for $24 \mathrm{~h}$ and subsequently treated with $1 \mu \mathrm{g} / \mathrm{ml}$ LPS for $24 \mathrm{~h}$, after which the cell-free supernatants were collected for LDH viability assays using LDH Assay kits (Nanjing Jiancheng Bioengineering Institute, Nanjing, China), according to the manufacturer's protocol. The optical density (OD) of the cell-free supernatants was measured using a Sunrise-Basic microplate reader (Tecan Group, Ltd., Männedorf, Switzerland) at $440 \mathrm{~nm}$.

Acridine orange (AO) double staining. DCMECs were transfected for $24 \mathrm{~h}$ and subsequently treated with $1 \mu \mathrm{g} / \mathrm{ml}$ LPS. After $24 \mathrm{~h}$, the cells was collected and washed three times with PBS and were adjusted to a density of $5 \times 10^{5}$ cells $/ \mathrm{ml}$. Subsequently, $4 \mu \mathrm{l}$ AO dye liquor (100 mg/l in PBS; Amresco, LLC) was added to $96 \mu \mathrm{l}$ cell suspension, after which the specimens were incubated in the dark for $30 \mathrm{~min}$ at room temperature. After rinsing three times with PBS, the cellular morphology was visualized and photographed using a CKX41 fluorescence microscope (Olympus Corporation), as previously described (6).

Reverse transcription-quantitative PCR (RT-qPCR). DCMECs were transfected for $24 \mathrm{~h}$. Transfected cells were treated with $1 \mu \mathrm{g} / \mathrm{ml}$ LPS for $24 \mathrm{~h}$. Total RNA was isolated using TRIzol ${ }^{\circledR}$ reagent (Invitrogen; Thermo Fisher Scientific, Inc.), according to the method described in a previous study (21). Total RNA was reverse transcribed into cDNA using PrimeScript Reverse Transcriptase (Takara Biotechnology Co., Ltd.), according to the manufacturer's protocol. The mRNA expression levels of various genes were quantified using SYBR premix Ex Taq ${ }^{\mathrm{TM}}$ (Takara Bio, Inc., Otsu, Japan), and the analysis was performed by the ABI
PRISM 7300 Real-Time PCR system (Applied Biosystems, Thermo Fisher Scientific, Inc.), as previously described (16). Primers used for RT-qPCR analysis are presented in Table I. The RT-qPCR conditions were as follows: $95^{\circ} \mathrm{C}$ for $30 \mathrm{sec}$, followed by 40 cycles of $95^{\circ} \mathrm{C}$ for $5 \mathrm{sec}$ and $60^{\circ} \mathrm{C}$ for $31 \mathrm{sec}$, according to the manufacturer's instructions. All target cDNA were analyzed in triplicate. The relative mRNA expression levels were quantified using the $2^{-\Delta \Delta \mathrm{Cq}}$ method.

Enzyme activity assay. The activities of FAS and ACC in the LPS-treated transfected DCMECs were analyzed using the Enzyme Activity Detection kit, according to the manufacturer's protocol. The OD of the microplate was read at $340 \mathrm{~nm}$ using a Sunrise-Basic microplate reader (Tecan Group, Ltd., Männedorf, Switzerland).

Western blot analysis. DCMECs were transfected for $24 \mathrm{~h}$, after which the cells were stimulated with $1 \mu \mathrm{g} / \mathrm{ml}$ LPS for 24 h. Subsequently, the cells were washed with cold PBS and ice-cold lysis buffer (Cell Signaling Technology Inc.), which contained $20 \mathrm{mM}$ Tris- $\mathrm{HCl}$ (pH7.5), $150 \mathrm{mM} \mathrm{NaCl}$, $1 \mathrm{mM} \mathrm{Na}{ }_{2}$ EDTA, $1 \mathrm{mM}$ EGTA, $1 \%$ NP-40, $1 \%$ sodium decxycholate, $2.5 \mathrm{mM} \beta$-glycerophosphate, $1 \mathrm{mM} \mathrm{Na}_{3} \mathrm{VO}_{4}$ and $1 \mu \mathrm{g} / \mathrm{ml}$ leupeptin. The cells were scraped and collected in a microfuge tube. Total protein was isolated from DCMECs using a method described in a previous study (22). Briefly, the protein concentration was measured using the bicinchoninic acid assay (Beyotime Institute of Biotechnology, Haimen, China), after which $30 \mu \mathrm{g}$ protein was separated by $10 \%$ sodium dodecyl sulfate-polyacrylamide gel electrophoresis and transferred onto nitrocellulose membranes using glycine transfer buffer (192 mM glycine, $25 \mathrm{mM}$ Tris- $\mathrm{HCl}$ (pH 8.8), $20 \%$ methanol) (both Bio-Rad Laboratories, Inc., Hercules, CA, USA). The membranes were blocked using blocking 
Table II. Effects of 14-3-3 $\gamma$ overexpression on cell viability and LDH activity in LPS-induced dairy cow mammary epithelial cells.

\begin{tabular}{|c|c|c|}
\hline Groups & Viability (\%) & LDH Viability (U/1) \\
\hline Control & $95.53 \pm 0.96$ & $52.05 \pm 4.31$ \\
\hline LPS & $56.21 \pm 0.73^{\mathrm{a}}$ & $125.7 \pm 12.13^{\mathrm{a}}$ \\
\hline pGCMV/IRES/EGFP-14-3-3 $\gamma+$ LPS & $70.49 \pm 0.81^{\mathrm{b}}$ & $105.2 \pm 5.63^{\mathrm{c}}$ \\
\hline pGCMV/IRES/EGFP + LPS & $59.89 \pm 0.81^{\mathrm{a}}$ & $129.12 \pm 10.38^{\mathrm{a}}$ \\
\hline
\end{tabular}

Data are presented as the mean \pm standard deviation of three independent experiments. ${ }^{\mathrm{a}} \mathrm{P}<0.05 \mathrm{vs}$. the control group; ${ }^{\mathrm{b}} \mathrm{P}<0.01 \mathrm{vs}$. the LPS group; ${ }^{\mathrm{P}}<0.01$ vs. the control group. LPS, lipopolysaccharide; LDH, lactate dehydrogenase; GCMV, grapevine chrome mosaic virus; IRES, internal ribosome entry site; EGFP, enhanced green fluorescent protein.

Table III. Effects of 14-3-3 $\gamma$ siRNA on cell viability and LDH activity in LPS-induced dairy cow mammary epithelial cells.

\begin{tabular}{lcc}
\hline Groups & Viability (\%) & LDH Viability (U/1) \\
\hline Control & $93.73 \pm 0.83$ & $60.05 \pm 5.81$ \\
LPS & $60.01 \pm 0.63^{\mathrm{a}}$ & $131.76 \pm 14.15^{\mathrm{a}}$ \\
siRNA-14-3-3 $\gamma+$ LPS & $50.56 \pm 0.59^{\mathrm{b}}$ & $155.62 \pm 8.64^{\mathrm{c}}$ \\
Negative control+LPS & $58.79 \pm 0.91^{\mathrm{a}}$ & $138.14 \pm 11.18^{\mathrm{a}}$ \\
\hline
\end{tabular}

Data are presented as the mean \pm standard deviation of three independent experiments. ${ }^{\mathrm{a}} \mathrm{P}<0.01$ vs. the control group; ${ }^{\mathrm{b}} \mathrm{P}<0.05$ vs. the LPS group; ${ }^{\mathrm{C}} \mathrm{P}<0.05$ vs. the control group. LPS, lipopolysaccharide; LDH, lactate dehydrogenase; siRNA, small interfering RNA.

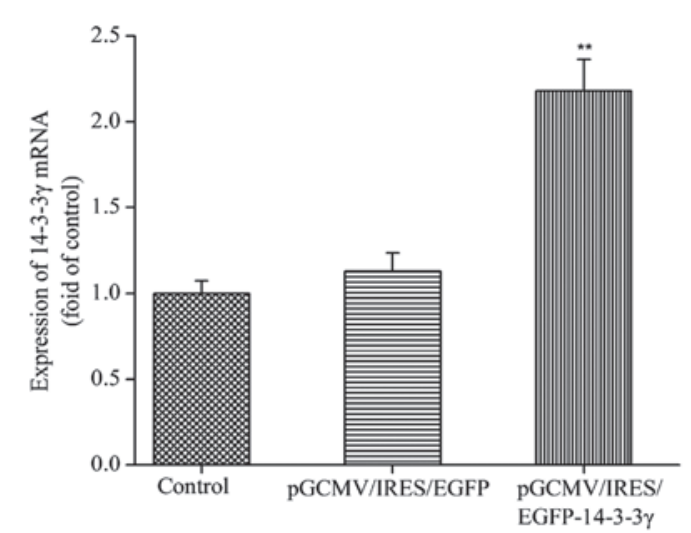

Figure 1. mRNA expression levels of 14-3-3 $\gamma$ in dairy cow mammary epithelial cells transfected with the pGCMV/IRES/EGFP-14-3-3 $\gamma$ expression vector for $24 \mathrm{~h}$. The relative mRNA expression levels of 14-3-3 $\gamma$ were determined using reverse transcription-quantitative polymerase chain reaction and were normalized to $\beta$-actin. Data are presented as the mean \pm standard deviation of three independent experiments. ${ }^{* *} \mathrm{P}<0.01$ vs. the control group. GCMV, grapevine chrome mosaic virus; IRES, internal ribosome entry site; EGFP, enhanced green fluorescent protein.

buffer (5\% nonfat dry milk) for $1.5 \mathrm{~h}$ at room temperature, and incubated with the following specific primary polyclonal antibodies at $4^{\circ} \mathrm{C}$ overnight at a dilution of 1:200: rabbit PPARG (sc-7196) and p-PPARG (sc-28001-R), and mouse SREBP1 (sc-365513), p-SREBP1 (9874) and $\beta$-actin (sc-8432). Following washing with TBST three times, the membranes were subsequently incubated with goat anti-mouse (bs-0296G) or anti-rabbit (bs-0295G) horseradish peroxidase-conjugated secondary antibodies at $37^{\circ} \mathrm{C}$ for $1.5 \mathrm{~h}$ at a dilution of $1: 1,000$. Antibody complexes were detected by enhanced chemiluminescence using the Super ECL Plus (Applygen Technologies, Inc., Beijing, China). Subsequently, the western blotting results were analyzed using a Tanon 1600R Gel Imaging System (Tanon Science and Technology Co., Ltd., Shanghai, China).

Statistical analysis. Quantitative data from the experiments are presented as the mean \pm standard deviation of triplicate experiments. Differences between mean values of normally distributed data were analyzed using one-way analysis of variance. Statistical analyses were conducted using the SPSS software, version 17.0 (SPSS, Inc., Chicago, IL, USA). P<0.05 was considered to indicate a statistically significant difference.

\section{Results}

mRNA expression levels of 14-3-3 $\gamma$ in transfected $D C M E C s$. In order to determine whether the recombinant pGCMV/IRES/EGFP-14-3-3 $\gamma$ expression vector had been successfully constructed, the mRNA expression levels of 14-3-3 $\gamma$ were detected. DCMECs were transfected with pGCMV/IRES/EGFP-14-3-3 $\gamma$ or pGCMV/IRES/EGFP for $24 \mathrm{~h}$, after which total RNA was extracted and analyzed by RT-qPCR The relative mRNA expression levels of 14-3-3 $\gamma$ in the DCMECs transfected with pGCMV/IRES/EGFP-14-3-3 $\gamma$ were significantly increased, as compared with the control group and pGCMV/IRES/EGFP group (P<0.01; Fig. 1). These results suggested that the pGCMV/IRES/EGFP-14-3-3 $\gamma$ expression vector was effectively expressed in cultured DCMECs.

14-3-3 $\gamma$ regulates the viability of LPS-induced DCMECs. In order to investigate whether 14-3-3 $\gamma$ was able to confer protection against LPS-induced DCMEC damage, pre-transfected cells were treated with $1 \mu \mathrm{g} / \mathrm{ml}$ LPS for $24 \mathrm{~h}$ and MTT and LDH activity assays were conducted to evaluate cell damage. Cell viability was significantly reduced, and LDH activity was significantly increased, in the LPS-treated DCMECs, as compared with the control group $(\mathrm{P}<0.01)$. However, 14-3-3 $\gamma$ overexpression significantly increased cell viability and decreased LDH activity in the LPS-induced DCMECs by 34.29 and $16.30 \%$ respectively, as compared with the LPS-treated group $(\mathrm{P}<0.01$ and $\mathrm{P}<0.05)$, respectively (Table II). Conversely, treatment with $14-3-3 \gamma$ siRNA significantly reduced the cell 
A
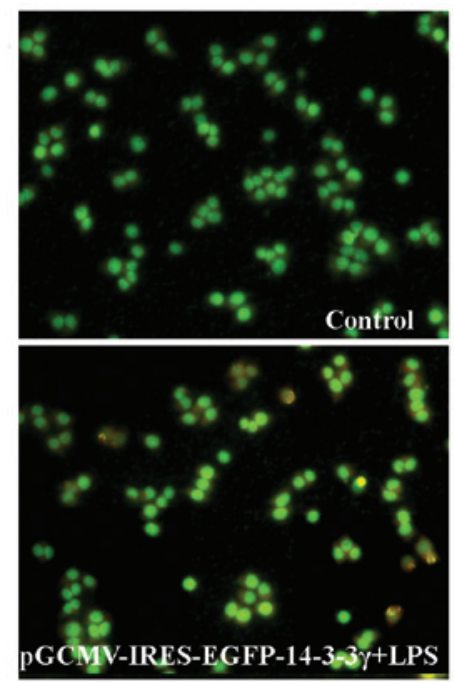

B

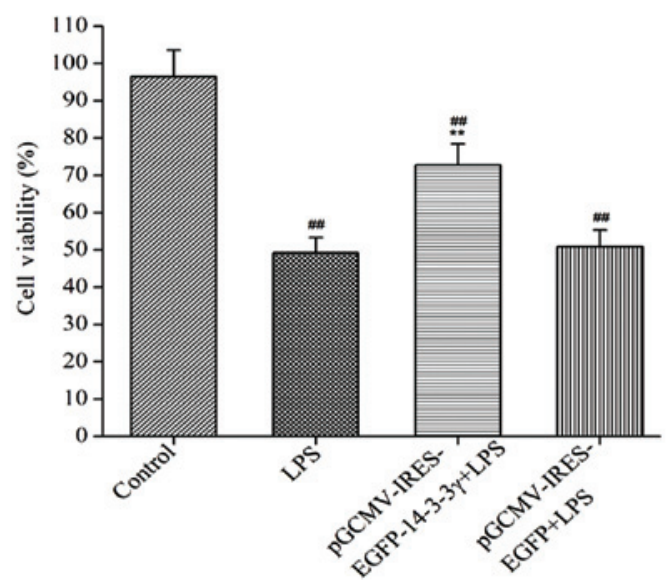

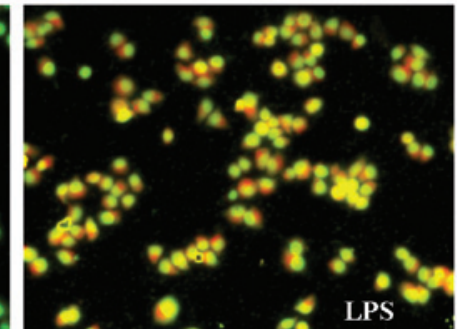
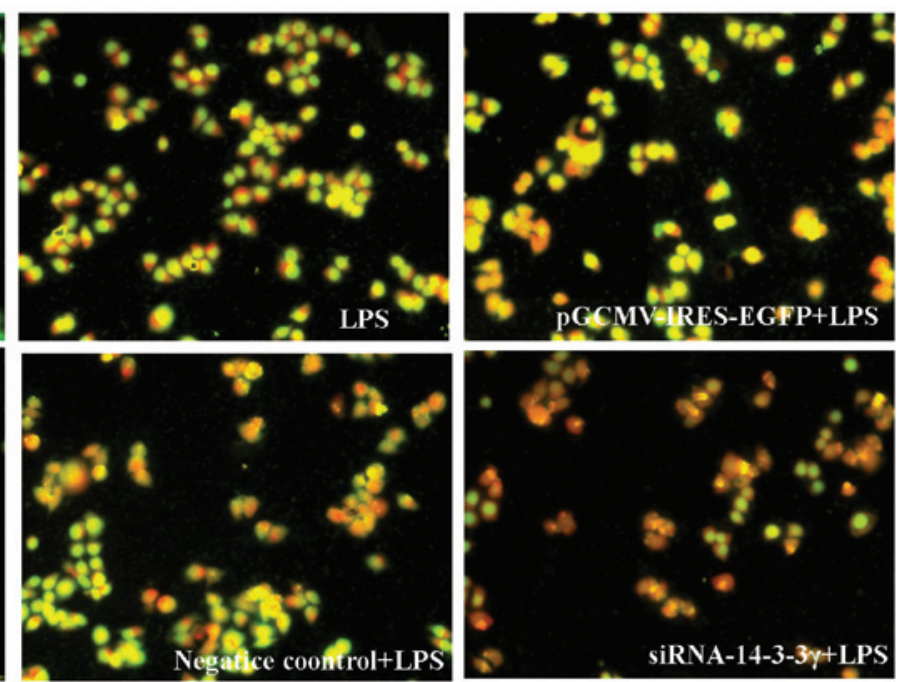

C

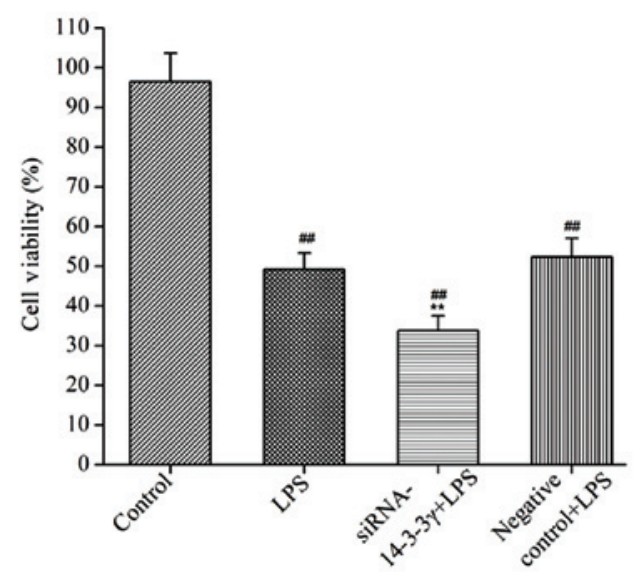

Figure 2. Effects of 14-3-3 $\gamma$ on LPS-induced dairy cow mammary epithelial cell (DCMEC) apoptosis. DCMECs were pre-transfected for $24 \mathrm{~h}$, after which the cells were stimulated with LPS $(1 \mu \mathrm{g} / \mathrm{ml})$ for $24 \mathrm{~h}$. (A) The morphological characteristics of apoptotic cells were visualized using fluorescence microscopy. DCMECs were transfected with (B) the pGCMV/IRES/EGFP-14-3-3 $\gamma$ expression vector or (C) 14-3-3 $\gamma$ siRNA. Cell viability was determined using the MTT assay. Data are presented as the mean \pm standard deviation of three independent experiments. ${ }^{*} \mathrm{P}<0.05$ and ${ }^{* *} \mathrm{P}<0.01$ vs. the LPS-treated group; ${ }^{*} \mathrm{P}<0.05$ and ${ }^{\# \#} \mathrm{P}<0.01$ vs. the control group. LPS, lipopolysaccharide; siRNA, small interfering RNA; GCMV, grapevine chrome mosaic virus; IRES, internal ribosome entry site; EGFP, enhanced green fluorescent protein.

A

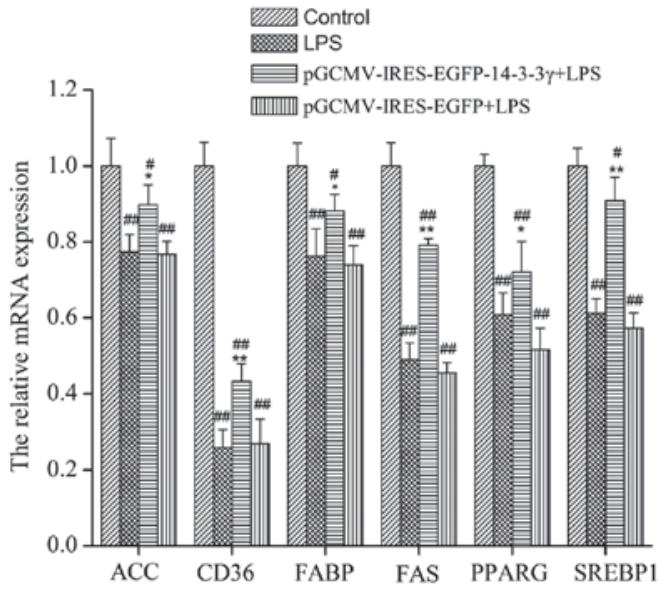

B

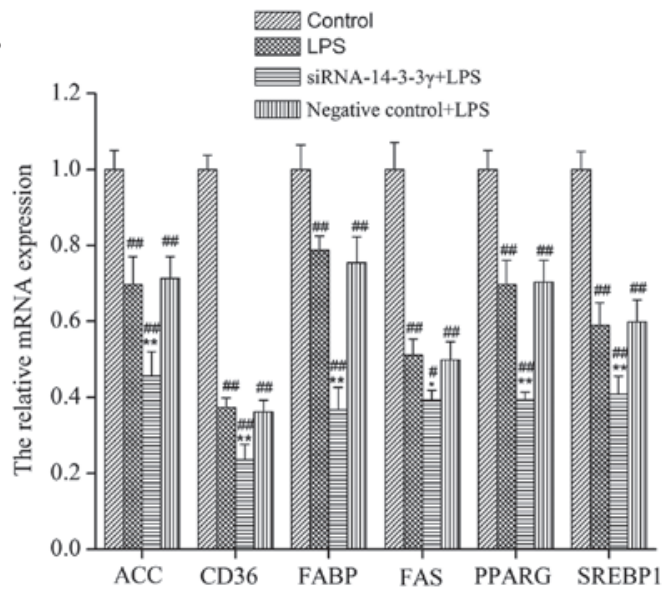

Figure 3. Effects of 14-3-3 $\gamma$ on the mRNA expression levels of genes associated with milk fat synthesis in LPS-induced dairy cow mammary epithelial cells (DCMECs). (A) DCMECs were transfected with pGCMV/IRES/EGFP-14-3-3 $\gamma$ or (B) siRNA-14-3-3 $\gamma$ for 24 h, after which the cells were stimulated with LPS $(1 \mu \mathrm{g} / \mathrm{ml})$ for $24 \mathrm{~h}$. The mRNA expression levels of SREBP1, PPARG, CD36, ACC, FAS and FABP were measured using reverse transcription-quantitative polymerase chain reaction, and were normalized to the $\beta$-actin gene. Data are presented as the mean \pm standard deviation of three independent experiments. ${ }^{*} \mathrm{P}<0.05$ and ${ }^{* *} \mathrm{P}<0.01$ vs. the LPS-treated group; ${ }^{\#} \mathrm{P}<0.05$ and ${ }^{\# \#} \mathrm{P}<0.01$ vs. the control group. LPS, lipopolysaccharide; SREBP1, sterol regulatory element binding protein-1; PPARG, peroxisome proliferator-activated receptor- $\gamma$; CD36, cluster of differentiation 36; ACC, acetyl-CoA carboxylase; FAS, fatty acid synthase; FABP, fatty acid binding protein; GCMV, grapevine chrome mosaic virus; IRES, internal ribosome entry site; EGFP, enhanced green fluorescent protein. 
A

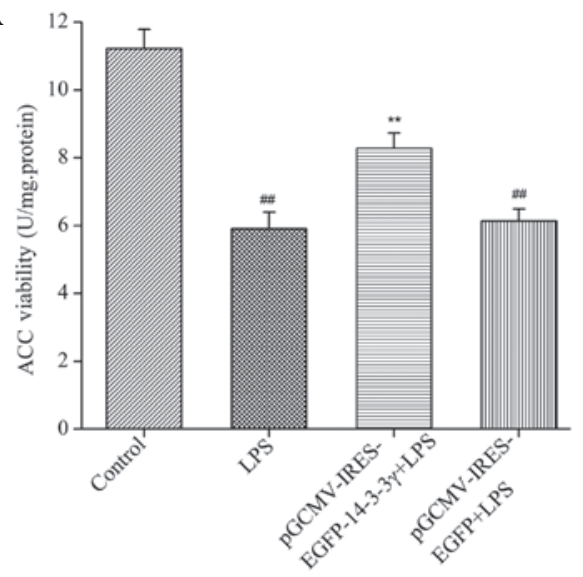

C

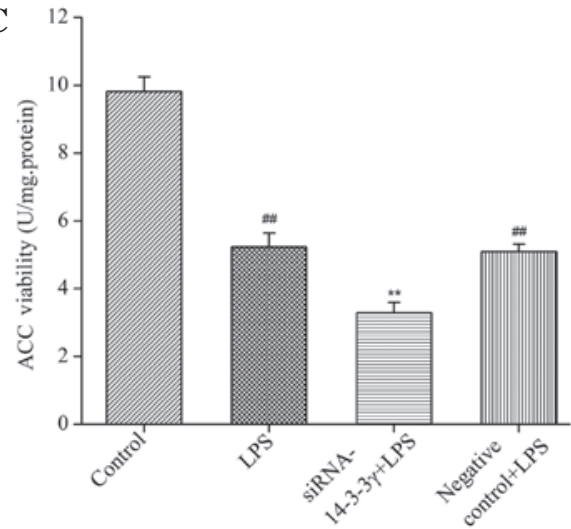

B

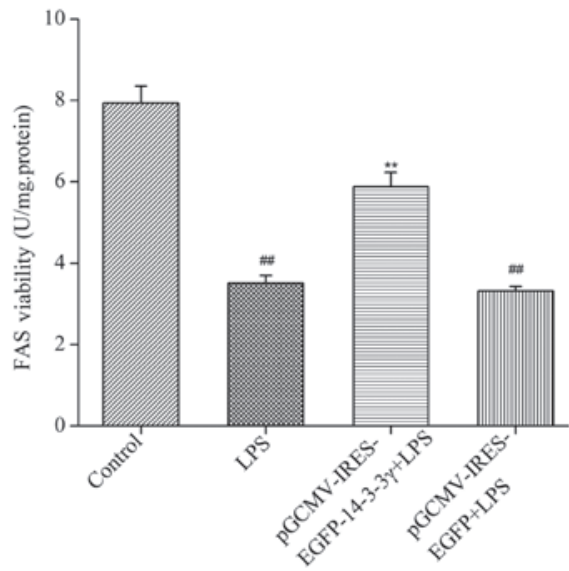

D

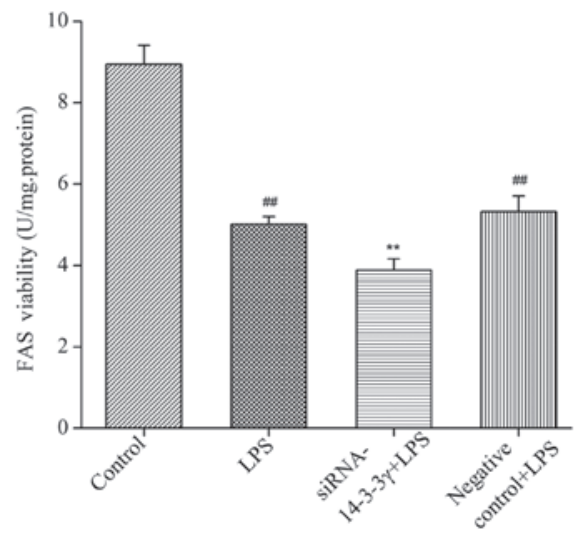

Figure 4. Effects of 14-3-3 $\gamma$ on the activities of FAS and ACC in LPS-induced dairy cow mammary epithelial cells (DCMECs). (A and B) DCMECs were transfected with the pGCMV/IRES/EGFP-14-3-3 $\gamma$ or pGCMV/IRES/EGFP expression vectors for $24 \mathrm{~h}$, after which the cells were stimulated with LPS (1 $\mu \mathrm{g} / \mathrm{ml})$ for $24 \mathrm{~h}$. The activities of (A) ACC and (B) FAS were measured using enzyme activity assays. (C and D) DCMECs were transfected with siRNA-14-3-3 $\gamma$ or a negative control for $24 \mathrm{~h}$, after which the cells were stimulated with LPS (1 $\mu \mathrm{g} / \mathrm{ml})$ for $24 \mathrm{~h}$. The activities of (C) ACC and (D) FAS were measured using enzyme activity assays. Data are presented as the mean \pm standard deviation of three independent experiments. ${ }^{* *} \mathrm{P}<0.01$ vs. the LPS-treated group; ${ }^{\# \#} \mathrm{P}<0.01$ vs. the control group. FAS, fatty acid synthase; ACC, acetyl-CoA carboxylase; LPS, lipopolysaccharide; siRNA, small interfering RNA; GCMV, grapevine chrome mosaic virus; IRES, internal ribosome entry site; EGFP, enhanced green fluorescent protein.

viability and increased the LDH activity in LPS-induced DCMECs by 15.74 and $18.10 \%$ respectively, as compared with the LPS-treated group $(\mathrm{P}<0.05)$, respectively (Table III). These findings suggested that $14-3-3 \gamma$ was capable of increasing cell viability in LPS-induced DCMECs.

14-3-3y regulates LPS-induced apoptosis in DCMECs. In order to evaluate the effect of 14-3-3 $\gamma$ on LPS-induced DCMEC apoptosis, the extent of apoptosis was analyzed morphologically by staining the cells with $\mathrm{AO}$ and performing fluorescence microscopy. Normal viable cells were dyed with $\mathrm{AO}$ and emitted uniform green fluorescence. Conversely, cells undergoing apoptosis emitted a yellow-green fluorescence and exhibited condensed or fragmented chromatin. In addition, 200 stained cells were randomly counted and viability was calculated as the percentage of the number of living cells, as compared with the total number of cells. LPS treatment significantly reduced the viability and increased the extent of apoptosis of DCMECs, as compared with the control group $(\mathrm{P}<0.01)$. Conversely, 14-3-3 $\gamma$ overexpression significantly increased the viability of the cells and decreased the extent of cell apoptosis, as compared with the LPS-treated group $(\mathrm{P}<0.01$; Fig. $2 \mathrm{~A}$ and $\mathrm{B})$. Following treatment with 14-3-3 $\gamma$ siRNA, opposite results were observed, as compared with those for the $14-3-3 \gamma$ recombinant plasmid (Fig. 2A and $\mathrm{C}$ ).

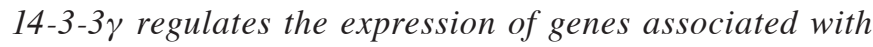
milk fat synthesis in LPS-induced DCMECs at the transcriptional level. In order to investigate the effects of 14-3-3 $\gamma$ on the mRNA expression levels of genes associated with milk fat synthesis in LPS-induced DCMECs, RT-qPCR was conducted. LPS significantly decreased the mRNA expression levels of SREBP1, PPARG, cluster of differentiation 36 (CD36), ACC, FAS and fatty acid binding protein (FABP), as compared with the control group $(\mathrm{P}<0.05)$. Conversely, the mRNA expression levels of these genes were significantly increased in LPS-induced DCMECs overexpressing 14-3-3 $\gamma$, as compared with the LPS group $(\mathrm{P}<0.01$; Fig. $3 \mathrm{~A})$, whereas treatment with siRNA-14-3-3 $\gamma$ significantly reduced the mRNA expression levels of these genes $(\mathrm{P}<0.05$; Fig. $3 \mathrm{~B})$.

14-3-3 $\gamma$ regulates the activities of FAS and ACC in $L P S$-induced DCMECs. In order to determine whether 14-3-3 $\gamma$ affects milk fat synthesis-associated enzymes in LPS-induced DCMECs, the activities of FAS and ACC were analyzed using enzyme activity assays. The activities of FAS and ACC were significantly increased in LPS-induced 

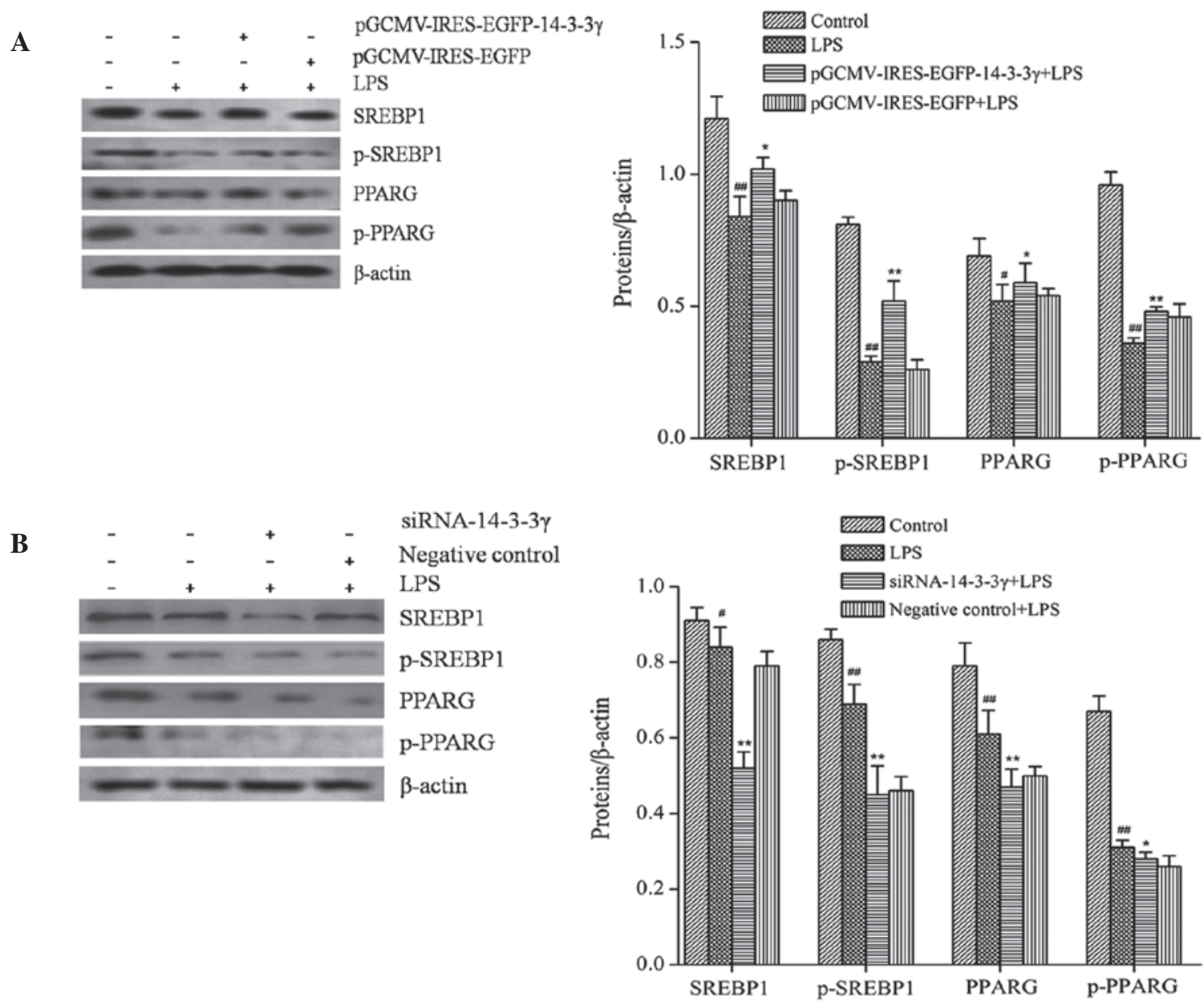

Figure 5. Effects of 14-3-3 $\gamma$ on the expression levels of milk fat synthesis-associated proteins in LPS-induced dairy cow mammary epithelial cells (DCMECs). DCMECs were transfected with (A) the pGCMV/IRES/EGFP-14-3-3 $\gamma$ or pGCMV/IRES/EGFP expression vectors or (B) siRNA-14-3-3 $\gamma$ or a negative control for $24 \mathrm{~h}$, after which the cells were treated with $1 \mu \mathrm{g} / \mathrm{ml}$ LPS for $24 \mathrm{~h}$. The protein expression levels of SREBP1, p-SREBP1, PPARG and p-PPARG were analyzed by western blotting. $\beta$-actin was used as an internal control. Data are presented as the mean \pm standard deviation of three independent experiments. ${ }^{*} \mathrm{P}<0.05$ and ${ }^{* *} \mathrm{P}<0.01$ vs. the LPS-treated group; ${ }^{\#} \mathrm{P}<0.05$ and ${ }^{\# \#} \mathrm{P}<0.01$ vs. the control group. LPS, lipopolysaccharide; SREBP1, sterol regulatory element binding protein-1; PPARG, peroxisome proliferator-activated receptor- $\gamma$; p-SREBP1, phosphorylated-SREBP1; p-PPARG, phosphorylated-PPARG; siRNA, small interfering RNA; GCMV, grapevine chrome mosaic virus; IRES, internal ribosome entry site; EGFP, enhanced green fluorescent protein.

DCMECs overexpressing 14-3-3 $\gamma$, as compared with the LPS group $(\mathrm{P}<0.01)$. Conversely, $14-3-3 \gamma$ siRNA significantly decreased the activities of FAS and ACC, as compared with the LPS group $(\mathrm{P}<0.01 ;$ Fig. 4). These findings suggested that 14-3-3 $\gamma$ was capable of increasing the activities of milk fat synthesis-associated enzymes in LPS-induced DCMECs.

14-3-3 $\gamma$ regulates the expression of proteins associated with milk fat synthesis in LPS-induced DCMECs. In order to investigate whether proteins involved in milk fat synthesis signaling pathways are regulated by 14-3-3 $\gamma$ in LPS-induced DCMECs, the protein expression levels of SREBP1, p-SREBP1, PPARG and p-PPARG were analyzed by western blotting. The protein expression levels of SREBP1 and PPARG in LPS-treated DCMECs were significantly decreased, as compared with the control group $(\mathrm{P}<0.05)$. Conversely, the protein expression levels of SREBP1 and PPARG were significantly increased in LPS-induced DCMECs overexpressing 14-3-3 $\gamma$, as compared with the LPS group ( $\mathrm{P}<0.05$; Fig. 5A), whereas 14-3-3 $\gamma$ siRNA significantly inhibited the expression of SREBP1 and PPARG proteins in LPS-induced DCMECs, as compared with the LPS group $(\mathrm{P}<0.01$; Fig. 5B). These findings suggested that $14-3-3 \gamma$ was capable of increasing the expression of proteins associated with milk fat synthesis in LPS-induced DCMECs.

\section{Discussion}

The present study investigated the protective effects of 14-3-3 $\gamma$ overexpression against LPS-induced damage in DCMECs, and demonstrated that a high level of $14-3-3 \gamma$ protein was able to attenuate LPS-induced apoptosis or death of DCMECs, and promote milk fat synthesis. Conversely, treatment of DCMECs with 14-3-3 $\gamma$ siRNA revealed opposed results; thus suggesting that $14-3-3 \gamma$ may have a potential role in preventing SARA-induced MFD.

Bacterial LPS concentrations are markedly increased during SARA (23). LPS, which is a major component of the outer membrane of gram-negative bacteria, is a highly efficient pro-inflammatory response factor that triggers a series of immune responses and results in the production of cytokines, including TNF- $\alpha$, IL-6 and IL-1 $\beta$ (24). In addition, LPS has been shown to significantly increase the mRNA expression 
levels of $\mathrm{NF}-\kappa \mathrm{B}(25,26)$. It has been reported that LPS is among the most potent microbial inducer of inflammation, which is a cascade of intracellular events that may initiate cell death (27). Furthermore, LPS has been shown to induce the activation of executioner caspases and other signaling cascades that ultimately lead to apoptosis and destruction of cells (28). Previous studies have implicated 14-3-3 proteins, a set of highly conserved scaffolding proteins, in the regulation of numerous important cellular processes, including the cell cycle, apoptosis and mitogenic signaling $(29,30)$. In addition, 14-3-3 proteins have been shown to have critical roles in various vital physiological and pathological processes by controlling the activity of their target proteins (31).

Our previous study (11) demonstrated that $14-3-3 \gamma$ may exert promising anti-inflammatory activity by downregulating the $\mathrm{NF}-\kappa \mathrm{B}$ and mitogen-activated protein kinase signaling pathways. In the present study, a pGCMV/IRES/EGFP-14-3-3 $\gamma$ expression vector was successfully constructed and transfected into DCMECs. After $24 \mathrm{~h}$, the cells were treated with $1 \mu \mathrm{g} / \mathrm{ml}$ LPS for $24 \mathrm{~h}$, after which the effects of LPS on DCMECs were analyzed using the MTT, LDH activity and AO double staining assays. It has previously been reported that the ability to produce milk is determined by the number and activity of secreting cells in ruminants (32). In the present study, LPS reduced the viability of DCMECs, increased the activity of $\mathrm{LDH}$, and promoted the apoptosis of DCMECs; thus indicating that LPS induced DCMECs injury. However, in the DCMECs transfected with pGCMV/IRES/EGFP-14-3-3 $\gamma$, 14-3-3 $\gamma$ overexpression significantly increased the viability of the LPS-induced cells and decreased the extent of apoptosis. Conversely, the inhibition of 14-3-3 $\gamma$ using 14-3-3 $\gamma$ siRNA significantly decreased the viability of LPS-induced DCMECs; thus suggesting that $14-3-3 \gamma$ may regulate LPS-induced cell viability. The results of the present study suggested that $14-3-3 \gamma$ overexpression may have protective effects against LPS-induced DCMECs injury.

SARA has been shown to affect both the viability of DCMECs, as well as their ability to lactate; in particular it has been shown to inhibit milk fat synthesis (10). It has been suggested that SARA may initiate the activation of systemic inflammatory responses and other essential metabolic disturbances of the host, leading to MFD. MFD is a syndrome characterized by a reduction in milk fat content (33-36). In a previous study, LPS stimulated lipolysis in adipose cells via the Toll-like receptor 4 and MEK1/2-ERK1/2 signaling pathway in the process of inhibiting milk fat synthesis (37). Previous studies have reported that LPS may affect milk fat synthesis, and indirectly downregulate the expression levels of the fatty acid transporter, via the release of proinflammatory cytokines (38-40). Our previous study demonstrated that 14-3-3 $\gamma$ overexpression was able to suppress the production of TNF- $\alpha$ and IL- 6 in cell culture supernatants. Therefore, since 14-3-3 $\gamma$ overexpression has been shown to suppress inflammation and increase the activity of cells, the present study hypothesized it may also improve the milk fat synthesis. In the present study, LPS significantly decreased the activities of key enzymes associated with de novo fatty acid synthesis, including FAS and ACC, in LPS-induced DCMECs, and this is consistent with a previous study (8). However, when the $14-3-3 \gamma$ protein was overexpressed in
DCMECs, the activities of FAS and ACC were significantly increased, whereas, the opposite results were observed when 14-3-3 $\gamma$ was inhibited using siRNA. These results suggested that $14-3-3 \gamma$ overexpressed was able to promote de novo fatty acid synthesis.

SREBP1 and PPARG have important roles in gene networks associated with milk fat synthesis, and have been shown to regulate the expression of numerous genes associated with milk fat synthesis (41). PPARG, which is a member of the nuclear receptor superfamily of transcription factors that have been shown to be responsible for the transcriptional regulation of fatty acid metabolism (42), is activated by lipophilic ligands and is important for maintaining the quality of milk by inhibiting the production of inflammatory lipids in lactating mammary glands (43). SREBP1 is a member of the basic helix-loop-helix transcription factor family, which are the major nuclear transcription factors that contribute to the regulation of milk fat synthesis (44). In the present study, LPS significantly decreased the expression levels of SREBP1 and PPARG in DCMECs, and this affect was attenuated by $14-3-3 \gamma$ overexpression in these cells. Conversely, the expression levels of SREBP1 and PPARG were significantly decreased in LPS-induced DCMECs transfected with pGCMV/IRES/EGFP-14-3-3 $\gamma$ following the inhibition of 14-3-3 $\gamma$ expression using siRNA. These results suggested that $14-3-3 \gamma$ was able to regulate genes associated with fatty acid metabolism in order to improve milk fat synthesis by increasing the expression levels of SREBP1 and PPARG in LPS-induced DCMECs.

In conclusion, the present study demonstrated that a high level of 14-3-3 $\gamma$ protein exerted protective effects against LPS-induced DCMEC injury, by increasing cell viability and promoting milk fat synthesis through the upregulation of SREBP1, PPARG, FAS, ACC, CD36 and FABP genes. It has previously been demonstrated that the expression levels of 14-3-3 $\gamma$ were affected by estrogen and prolactin (16); thus suggesting that the addition of nutrients to the dairy cow diet during lactation may allow the expression levels of 14-3-3 $\gamma$ to be regulated, in order to prevent SARA-induced MFD.

\section{Acknowledgements}

The present study was supported by the Major State Basic Research Development Program of China (program 973; grant no. 2011CB100804) and the National High Technology Research and Development Program of China (program 863; grant no. 2006AA10Z1A4).

\section{References}

1. Plaizier JC, Krause DO, Gozho GN and McBride BW: Subacute ruminal acidosis in dairy cows: The physiological causes, incidence and consequences. Vet J 176: 21-31, 2008.

2. Gozho GN, Krause DO and Plaizier JC: Ruminal lipopolysaccharide concentration and inflammatory response during grain-induced subacute ruminal acidosis in dairy cows. J Dairy Sci 90: 856-866, 2007.

3. Waldron MR, Nishida T, Nonnecke BJ and Overton TR: Effect of lipopolysaccharide on indices of peripheral and hepatic metabolism in lactating cows. J Dairy Sci 86: 3447-3459, 2003.

4. Sweet MJ and Hume DA: Endotoxin signal transduction in macrophages. J Leukoc Biol 60: 8-26, 1996. 
5. Zandi E, Rothwarf DM, Delhase M, Hayakawa M and Karin M The IkappaB kinase complex (IKK) contains two kinase subunits, IKKalpha and IKKbeta, necessary for IkappaB phosphorylation and NF-kappaB activation. Cell 91: 243-252, 1997.

6. Ansari N, Khodagholi F, Amini M and Shaerzadeh F: Attenuation of LPS-induced apoptosis in NGF-differentiated PC12 cells via NF-kB pathway and regulation of cellular redox status by an oxazine derivative. Biochimie 93: 899-908, 2011.

7. Ling B and Alcorn J: LPS-induced inflammation downregulates mammary gland glucose, fatty acid, and L-carnitine transporter expression at different lactation stages. Res Vet Sci 89: 200-202, 2010.

8. Zebeli Q and Ametaj BN: Relationships between rumen lipopolysaccharide and mediators of inflammatory response with milk fat production and efficiency in dairy cows. J Dairy Sci 92: 3800-3809, 2009

9. Waggoner JW, Löest CA, Turner JL, Mathis CP and Hallford DM: Effects of dietary protein and bacterial lipopolysaccharide infusion on nitrogen metabolism and hormonal responses of growing beef steers. J Anim Sci 87: 3656-3668, 2009.

10. Zhang YD, Wang JQ and Hu T: Infusion of lipopolysaccharide into external pudendal artery of lactating dairy cows: Effects on milk composition and milk fat constituents. Dong Wu Ying Yang Xue Bao 23: 1317-1323, 2011

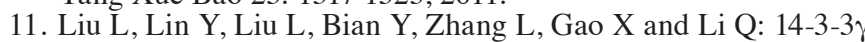
regulates lipopolysaccharide-induced inflammatory responses and lactation in dairy cow mammary epithelial cells by inhibiting $\mathrm{NF}-\kappa \mathrm{B}$ and MAPKs and up-regulating mTOR signaling. Int J Mol 16: 16622-16641, 2015.

12. López-Soriano FJ and Williamson DH: Acute effects of endotoxin (lipopolysaccharide) on tissue lipid metabolism in the lactating rat. The role of delivery of intestinal glucose. Mol Cell Biochem 141: 113-120, 1994.

13. Hosing AS, Kundu ST and Dalal SN: 14-3-3 Gamma is required to enforce both the incomplete S phase and G2 DNA damage checkpoints. Cell Cycle 7: 3171-3179, 2008.

14. Pozuelo-Rubio M: Proteomic and biochemical analysis of 14-3-3-binding proteins during C2-ceramide-induced apoptosis. FEBS J 277: 3321-3342, 2010

15. van Hemert MJ, Steensma HY and van Heusden GP: 14-3-3 proteins: Key regulators of cell division, signalling and apoptosis. Bioessays 23: 936-946, 2001.

16. Huang JG: Proteomic analysis of the lactation regulation in DCMECs treated with different hormones (unpublished $\mathrm{PhD}$ thesis). Northeast Agricultural University, Harbin, China, 2012.

17. Liu D, Yin D, Yan GH, Sun D, Xu M and He M: Protective role of 14-3-3 $\gamma$ in burn and LPS-induced rat myocardial injury. Zhong Guo Bing Li Sheng Li Za Zhi 28: 1160-1165, 2012 (In Chinese).

18. Liu D, Yin D, Sun D, Xu M and He M: The Role of Bax in the 14-3-3 $\gamma$ protection against cardiomyocyte damage induced by LPS. Tian Jin Yi Yao 40: 1222-1225, 2012 (In Chinese).

19. Zhao K, Liu HY, Zhou MM and Liu JX: Establishment and characterization of a lactating bovine mammary epithelial cell model for the study of milk synthesis. Cell Biol Int 34: 717-721, 2010.

20. Li HM, Wang CM, Li QZ and Gao XJ: MiR-15a decreases bovine mammary epithelial cell viability and lactation and regulates growth hormone receptor expression. Molecules 17: 12037-12048, 2012

21. Lu LM, Li QZ, Huang JG and Gao XJ: Proteomic and functional analyses reveal MAPK1 regulates milk protein synthesis. Molecules 18: 263-275, 2012

22. Zhang Q, Zhao XH and Wang ZJ: Cytotoxicity of flavones and flavonols to a human esophageal squamous cell carcinoma cell line (KYSE-510) by induction of $\mathrm{G} 2 / \mathrm{M}$ arrest and apoptosis. Toxicol In Vitro 23: 797-807, 2009.

23. Khafipour E, Krause DO and Plaizier JC: A grain-based subacute ruminal acidosis challenge causes translocation of lipopolysaccharide and triggers inflammation. J Dairy Sci 92 1060-1070, 2009.

24. Bruckmaier RM: Gene expression of factors related to the immune reaction in response to intramammary Escherichia coli lipopolysaccharide challenge. J Dairy Res 72: 120-124, 2005.
25. Cheng G, Zhao Y, Li H, Wu Y, Li X, Han Q, Dai C and $\mathrm{Li}$ Y: Forsythiaside attenuates lipopolysaccharide-induced inflammatory responses in the bursa of Fabricius of chickens by downregulating the NF-kB signaling pathway. Exp Ther Med 7: 179-184, 2014.

26. Reddy DB and Reddanna P: Chebulagic acid (CA) attenuates LPS-induced inflammation by suppressing NF-kappaB and MAPK activation in RAW 264.7 macrophages. Biochem Biophys Res Commun 381: 112-117, 2009.

27. Wong PM, Chugn SW and Sultzer BM: Genes, receptors, signals and responses to lipopolysaccharide endotoxin. Scand J Immunol 51: 123-127, 2000.

28. Yang F, Sun X, Beech W, Teter B, Wu S, Sigel J, Vinters HV, Frautschy SA and Cole GM: Antibody to caspase-cleaved actin detects apoptosis in differentiated neuroblastoma and plaque-associated neurons and microglia in Alzheimer's disease. Am J Pathol 152: 379-389, 1998.

29. Radhakrishnan VM and Martinez JD: 14-3-3gamma induces oncogenic transformation by stimulating MAP kinase and PI3K signaling. PLOS One 5: 11433, 2010.

30. Samuel T, Weber HO, Rauch P, Verdoodt B, Eppel JT, McShea A, Hermeking $\mathrm{H}$ and Funk JO: The G2/M regulator 14-3-3sigma prevents apoptosis through sequestration of Bax. J Biol Chem 276: 45201-45206, 2001.

31. Obsilova V, Silhan J, Boura E, Teisinger J and Obsil T: 14-3-3 proteins: A family of versatile molecular regulators. Physiol Res 57 (Suppl 3): S11-S21, 2008.

32. Boutinaud M, Guinard-Flamenta J and Jammes H: The number and activity of mammary epithelial cells, determining factors for milk production. Reprod Nutr Dev 44: 499-508, 2004.

33. Ametaj BN, Emmanuel DG, Zebeli Q and Dunn SM: Feeding high proportions of barley grain in a total mixed ration perturbs diurnal patterns of plasma metabolites in lactating dairy cows. J Dairy Sci 92: 1084-1091, 2009.

34. Zebeli Q, Dunn SM and Ametaj BN: Perturbations of plasma metabolites correlated with the rise of rumen endotoxin in dairy cows fed diets rich in easily degradable carbohydrates. J Dairy Sci 94: 2374-2382, 2011.

35. Mao SY, Zhang RY, Wang DS and Zhu WY: Impact of subacute ruminal acidosis (SARA) adaptation on rumen microbiota in dairy cattle using pyrosequencing. Anaerobe 24: 12-19, 2013.

36. Kleen JL, Hooijer GA, Rehage J and Noordhuizen JP: Subacute ruminal acidosis (SARA): A review. J Vet Med A Physiol Pathol Clin Med 50: 406-414, 2003

37. Zu L, He J, Jiang H, Xu C, Pu S and Xu G: Bacterial endotoxin stimulates adipose lipolysis via toll-like receptor 4 and extracellular signal-regulated kinase pathway. J Biol Chem 284: 5915-5926, 2009.

38. Ling B and Alcorn J: LPS-induced inflammation downregulates mammary gland glucose, fatty acid, and L-carnitine transporter expression at different lactation stages. Res Vet Sci 89: 200-202, 2010.

39. López-Soriano FJ and Williamson DH: Acute effects of endotoxin (lipopolysaccharide) on tissue lipid metabolism in the lactating rat. The role of delivery of intestinal glucose. Mol Cell Biochem 141: 113-120, 1994.

40. Pekala PH, Kawakami M, Angus CW, Lane MD and Cerami A: Selective inhibition of synthesis of enzymes for de novo fatty acid biosynthesis by an endotoxin-induced mediator from exudate cells. Proc Natl Acad Sci USA 80: 2743-2747, 1983.

41. Bionaz $\mathrm{M}$ and Loor JJ: Gene networks driving bovine milk fat synthesis during the lactation cycle. BMC Genomics 9: 366 , 2008.

42. Yang Q and Li Y: Roles of PPARs on regulating myocardial energy and lipid homeostasis. J Mol Med (Berl) 85: 697-706, 2007.

43. Wan Y, Saghatelian A, Chong LW, Zhang CL, Cravatt BF and Evans RM: Maternal PPAR gamma protects nursing neonates by suppressing the production of inflammatory milk. Genes Dev 21: 1895-1908, 2007.

44. Anderson SM, Rudolph MC, McManaman JL and Neville MC: Key stages in mammary gland development. Secretory activation in the mammary gland: It's not just about milk protein synthesis! Breast Cancer Res 9: 204, 2007. 